Michael E. Goldberg MD,

Harry M. Rosenblum MD, Joseph L. Seltzer MD, Francis E. Rosato MD

\title{
Isolated regional perfusion; anaesthetic technique, monitor- ing and blood replacement
}

Isolated regional perfusion for the treatment of malignam melanoma is an accepted method of trealment. No standard of anciesthetic practice has been estabbished for those individuals. Perioperative records of patients undergoing isolated limb perfision were studied to determine adequate blood replacement. Records were examined and compared for (I) age, (2) ASA physical stalus, (3) presence of associated disense, (4) anaesthetic rechnique, (5) the amount of blood and fuid replacement. (6) preoperative haemoglobin (hgb) and haentatocrit (het) and pastoperative serial complete blood counts. Fifteen patients were studied (mean age $53 \pm 16 \mathrm{grs}$ ). Mean blood and fluid replacement was: packed red blood cells; $2.28 \pm 0.82$ units, $722 \pm 17 \mathrm{ml}$ of 5 per cent albumin, $1747=21 \mathrm{ml}$ crystalloid. There were twelve Physical Status Class I or II and three Class III patientr. All patients received genteral antesthesia. There was a statistically significant difference in the preoperative and postoperative values for haemoglobin and haematocrit $(p<0.01)$ with no difference besween the

\section{Key words}

SURGERY: isolated regional perfusion; MONITORING: fluid replacement, haemodilution; ANAFSTHETIC TECHNIQUE: isolated regional perfusion

From the Departments of Ancsthesiology and Surgery Jefferson Medical College, Thomas Jefferson University, Philadelphia, Pennsylvania.

Address correspondence to: Dr. Michael E.

Goldberg, c/o Department of Anesthesiology, Thomas Jefferson University Hospital, 111 S. 11 th Street, Suite 6275, Philadelphia, Pennsylvania 19107. postoperative and discharge values. Adequate blood replacement was determined by the equation:

Washout hat $\times$ volume of washout

Patient's preop ha

Extensive invasive monitoring is not routinely required for adequate blood replacement or the detection of leaks between the syrtemic and isolated circulation.

Isolated regional perfusion for primary and recurrent malignant melanoma of the extremity has become an accepted therapeutic modality. The concept of intra-arterial chemotherapy for malignancy was first introduced by Klope et al. ${ }^{1}$ Creech $^{2}$ combined this procedure with an extra-corporeal circuit and bubble oxygenator to provide a means of temporarily isolating a cumour-bearing area while it is being perfused with an alkylating agent, thereby limiting systemic toxicity. As a result of the studies by Stehlin, Giovanella et al., ${ }^{3-5}$ hyperthermia was added to the perfusion system. Their studies suggested that hyperthermic perfusion stinulated the immune cytoxic response against the melanoma cells. Many chemotherapeutic agents have been tried in the perfusion system, but to date, L-Phenylalanine Mustard (LPAM) is felt to be the most active single agent to inhibit the growth of maligant melanoma, as shown in the original animal experiments of Luck. ${ }^{6}$

The staging methods outlined by Clark, ${ }^{7}$ Breslow, ${ }^{8}$ and the M.D. Anderson Hospital ${ }^{9}$ have contributed significantly to rational treatment protocols. Improved survival with lower recurrence rates as a result of regional perfusion has been documented by several authors. ${ }^{5-7}$ McBride and 
Clark, ${ }^{13}$ reported an increase in the five-year survival rates with surgical treatment alone from 71 per cent and 38 per cent in patients with Stage $l$ and II disease respectively, to 86 and 57 per cent by surgery and isolated hyperthermic perfusion. McBride ${ }^{9}$ also reported a diminution in the recurrence rates by 12 per cent in upper extremity melanomas, and by 14 per cent with lower extremity melanomas using surgery and isolated perfusion. For more advanced melanomas (IIla, Illb, IIlab) McBride showed improved survival rates using triple drug perfusions (LPAM, Actinomycin D, Nitrogen Mustard) rather than LPAM alone. More recently Janotf et $a .^{12}$ reported on the superiority of hyperthermic isolation perfusion, wide local excision and regional lymphadenectomy.

The anaesthetic management of those patients can be complex and no standarc of practice has been established. Cruchley et al. ${ }^{18}$ discussed two cases in which they suggested that extensive invasive monitoring was indicated. We reviewed the perioperative records of patients undergoing isolated limb perfusion, to determine adequate blood replace ment for those patients without the use of invasive monitoring, and if more invasive monitoring was indicated.

\section{Methods}

The study involved 15 adult patients over a threeyear period. The surgery was al ways performed by one of the authors (FER). Anaesthetic and hospital records were examined and compared for: (1) age, (2) ASA physical status, (3) presence of associated diseases, (4) anaesthetic technique, (5) the amount of blood lost and the blood and fluid replacement, (6) preoperative and postoperative serial haemoglobin, hacmatocrit and white blood cell counts. Limb perfusion technique includes insertion of a cannulae into the femoral artery and vein just below the inguinal ligament, or brachial artery and vein just distal to the pectoralis minor muscle. The cannulae are connected to a Travenol* low How perfusion pump and a Bentley $\leftarrow$ BOS $2 S$ pediatric bubble through oxygenator with a heat exchanger.

*Travenol Laboratories Inc. Cardiopulmonary Product Division Deerfield, IL 60015.

†Bentley Corporation, 17502 Armstrong Ave Irvine CA 92714 .
Pump prime consists of one litre of Plasmalyte, $\dagger$ a balanced electrolyte solution and 2000 units of heparin. The prime is heated to $40^{\circ} \mathrm{C}$ before perfusion. Isolation of the extremity is achieved with occlusive vascular clamps placed proximal to the perfusion cannulae, as well as a proximal tourniquet fashioned from a Penrose drain placed around the extremity. Heparinization for those cases was achieved by way of the pump prime and thus limited to the perfused limb. No further heparin is administered unless complications arise which would dictate this necessity. We systemically heparinized only one of our patients because of vessel spasm and the need for a right fernoral embolec. tomy.

When limb perfusion is started flow rates of 200 to $600 \mathrm{ml}$ per minute are achieved and maintained during the course of the peffusion. For a single leg perfusion the average flow rate is approximately 250-300 ml per minute and for upper extremities the rate is $150 \mathrm{ml}$ per minute. The flow rate is limited by the size of the vessel which is cannulated and the resistance in the infusion line. Our rates are consistent with those described in the literature. ${ }^{17-19}$

One patient had nuclear scan with 150 micro currie of radioiodinated serum albumin injected into the limb perfusate and a scintillation counter over the chest. This procedure has also been performed in other institutions to monitor for leak of perfusate into the systemic circulation. ${ }^{9,20}$

After ten minutes of perfusion of the isolated limb three aliquots of LPAM are given into the arterial side at five-minute intervals. The total dose utilized is $60 \mathrm{mg}$ per meter squared body surface area for the leg and $30 \mathrm{mg}$ per meter squared boy surface area for the arm. Fifteen minutes after the last dose of LPAM the extremity is washed out with three to four litres of lactated Ringers solution. The vessels are then decannulated, sutured and the procedure is terminated. At this time the haemoglobin, haematocrit and volume of blood washed out into the reservoir is determined. These values are used to determine proper blood replacement from the formula:

$$
\begin{aligned}
\text { Washout hct } \times \text { volume of washout }(\mathrm{ml}) \\
\text { Patient's preop hct } \\
=\mathrm{ml} \text { of blood lost }
\end{aligned}
$$

$\ddagger$ Traveno? Laboratories Inc. Deerfield IL 60015. 


\section{Results}

The mean age of the patients studied was $53 \pm 16$ years. All patients were ASA physical status class I, II or III. Three patients had significant associated diseases. The first had a history of hypertension which was controlled by dietary restrictions without medication. The second patient had a history of diabetes mellitus controlled by diet, hypertension controlled with a single medication, arthritis and a hiatus hernia. The third patient had a radical mastectomy five years prior to admission. On this admission she had anemia, a pleural effusion and bony metastasis to her ribs and leg. Intraoperatively all patients had blood pressure detemnined by sphygomanometry, heart rate and cardiac electrical changes by electrocardiogram, an esophageal stethoscope or precordial stethoscope and in 14 of 15 cases a temperature probe was inserted into the nasopharynx. Two patients had a central venous catheter inserted via the antecubital fossa. One was the patient previously mentioned with diabetes mellitus and a labile hypertensive. The second was the patient with a previous radical mastectomy who at this time had pleural effusions and anemia. None of the patients studied had an arterial cannula or a pulmonary artery catheters. All lesions were Clarks level III or IV. ${ }^{6,7,9}$ All inductions were performed with thiopentone, a narcotic and a muscle relaxant. Seven of the cases were maintained with a nitrous oxide, muscle relaxant, narcotic technique while eight received enflurane. The mean estimated blood loss was $1360 \pm 24 \mathrm{ml}$. Blood and fluid replacement is given in Table 1 .

There were two instances of major complications during the procedure (see Table II). The first involved a major leak to the pump. This was apparent from an increase in the reservoir amount of blood and correlated with a drop in systemic blood pressure of 40 torr systolic. Perfusion was stopped immediately and rapid infusion of four units of packed red blood cells along with $500 \mathrm{ml}$ of five per cent albumin, in addition to $10 \mathrm{mg}$ of ephedrine IV. Once the blood pressure stabilized, the clamps and

TABLE I Mean blood and fluid replacement during intraoperative jeriod

\begin{tabular}{lr}
\hline Blood (PRBC's) & $2.28 \pm 0.82$ units \\
$5 \%$ albumin & $722 \pm 17 \mathrm{ml}$ \\
Crystalloid & $1747 \pm 20 \mathrm{ml}$ \\
\hline
\end{tabular}

tourniquet were readjusted and perfusion resumed without incident. The second patient had a drop in blood pressure of 20 torr systolic. This was treated with intravenous ephedrine $15 \mathrm{mg}$ in divided doses with return of pressure to normal and without any evidence of increase in reservoir fluid. The range, mean and standard deviation of preoperative, postoperative and discharge blood values are listed in Table III.

\section{Discussion}

Only general anaesthesia has been previously described for isolated limb perfusion. ${ }^{18}$ Similarly, on our service only general anaesthesia has been utilized. Regional anaesthesia might well be a viable alternative in cases where systemic heparinization is not used. However, spinal and epidural anaesthesia is associated with some degree of sympathetic block. If the patient's systemic blood pressure were to drop below the pressure perfusing the isolated leg it is theoretically possible that a leak could into the systemic circulation. Therefore hypotension should be prevented or treated vigourously if spinal or epidural anaesthesia is used. Sciaticlumbar plexus block might have to be supplemented with local infiltration to allow cannulation in the femoral triangle. Likewise, a separate block of $T_{2}$ or local infiltration would be necessary to operate in the axilla.

Radioisotope studies are performed at several institutions in order to monitor for possible drug leakage to the systemic circulation. ${ }^{9,20}$ This procedure has also been performed at our institution in the past. An acceptable leak of chemotherapeutic agent to the systemic circulation is felt to be up to 15-20 per cent, yet our leak has never been demonstrated to be greater than 1.5 per cent. As a result the use of radioisotopes has been abandoned at our institution as routine intraoperative monitoring.

Monitors utilized during the procedure at our institution consisted of sphygmomanometry, electrocardiogram and precordial or oesophageal stethescope in all cases. The use of oropharyngeal temperature probes was recorded in 14 of the 15 patients; however, we feel that temperature monitoring should be routine for all cases. Two of the patients had central venous catheters inserted. No patient was deemed ill enough to warrant pulmonary artery of arterial catheter placement. However, if the patients' preoperative evaluation demon- 
TABLE II Summary of patient management

\begin{tabular}{|c|c|c|c|c|}
\hline Patient \# & Change in reservoir volume? & Change in $B P$ & Inotrope & Maintenance technique \\
\hline $\mathbf{I}$ & Increase of $500 \mathrm{ml}$ once steady flow reached & 80 systolic & Ephedrine $10 \mathrm{mg} \mathrm{IV}$ & Balanced \\
\hline 2 & No change & No change & None & Enflurane \\
\hline 3 & No change & No change & None & Enflurane \\
\hline 4 & No change & No change & None & Enflurane \\
\hline 5 & No change & No change & None & Balanced \\
\hline 6 & Wo change & No change & None & Balanced \\
\hline 7 & No change & No change & None & Balanced \\
\hline 8 & No change & $\begin{array}{l}\text { Dropped from } 100 \text { to } \\
80 \text { torr systolic }\end{array}$ & Ephedrine $15 \mathrm{mg} \mathrm{IV}$ & Balanced \\
\hline 9 & No change & No change & None & Enflurane \\
\hline 10 & No change & No change & None & Balanced \\
\hline 11 & No change & No change & None & Enflurane \\
\hline 12 & No change & No change & None & Enflurane \\
\hline 13 & No change & No change & None & Enflurane \\
\hline 14 & No change & No change & None & Enflurane \\
\hline 15 & No change & No change & None & Balanced \\
\hline
\end{tabular}

Table Il Summary of changes noted in the reservoir blond volume once steady flow state was reached, and significunt changes in blond pressure (decrease of $20 \%$ from immediate preoperative values or less than 80 uor and/or increase of $20 \%$ over the immediate preoperative period or greater than $160 / 90$ ). Balanced anaesthesia $=\mathrm{N}_{2} \mathrm{O}$ /narcotic and muscic relaxant. Systemic heparinization was not employed, except for patient \# 10 who received 5,000 units of heparin.

TABLE III Hacmatological results

\begin{tabular}{|c|c|c|c|c|c|c|c|c|c|}
\hline & \multicolumn{3}{|l|}{ Preoperarive } & \multicolumn{3}{|l|}{ Pastoperative } & \multicolumn{3}{|l|}{ Discharge } \\
\hline & $H G B$ & $H C T$ & $W B C$ & $H G B$ & $H C T$ & $W B C$ & $H G B$ & $H C T$ & $W B C$ \\
\hline Range & $9.2-14.7$ & $28.4-48.2$ & $5.8-21,8$ & $8.2-14.3$ & $24.6-41.4$ & $6.0-20.4$ & $7.2-13.8$ & $20.1-40.9$ & $3.9-13.8$ \\
\hline Mean & $13.59 \pm 1.6$ & $40.1 \pm 4.5$ & $9.0 \pm 4.0$ & $11.57=2.0^{*}$ & $33.7 \pm 5.6^{*}$ & $12.3 \pm 4.0$ & $11.02 \pm 1.95$ & $32.0 \pm 6.0$ & $7.5 \pm 2.8$ \\
\hline
\end{tabular}

The mean initial, immediate postoperative, and discharge haemoglobin, hacmatocrit and wbe values are shown along with the standard deviation and range of these values.

${ }^{*} \mathrm{p}<0.01$ compared to preop values.

strated a significant disease state in which the cardiovascular system was compromised, then this would have been performed. The indications for invasive monitoring are outlined by Cruchley et al. ${ }^{18}$

Similar to Cruchley et al., ${ }^{18}$ we also attempt to maintain pump prime at a low level to prevent haemodilution. We utilized one litre of Plasmalyte (with 2000 units of heparin) which is the minimum amount of prime required for the Bentley BOS 2S pediatric oxygenator. Our limb flow was determined by the size of the vessel cannulated and resistance in the flow line. In other words, the flow is determined by the line pressure which is ultimately determined by the size of the arterial cannulae. Even if the leg is vasodilated, there would not be an increase in flow because of the cannula size. We have expcrienced no problems reaching maximum flow. The flows we utilize comply with those flows described by authors from other institutions. ${ }^{17-19}$

We did not systemically heparinize our patients unless there was an indication to do so. This would include a prolonged perfusion time (we consider this to be greater than one hour) as well as other medically indicated uses of systemic heparinization. In our series the need for systemic heparinization arose when pulses were absent in the right foot of one of the patients during the procedure. A right femoral embolectomy was performed successfully. The patient had a weak dorsalis pedis pulse on the right at discharge. The argument in favour of 
TABLE IV Postoperative complications

\begin{tabular}{ll}
\hline Patient \# & Postoperative romplication \\
\hline 1 & Poor palpable dorsalis pedis (DP) nausea, and posterior tibial pulse resolved by day 3 \\
2 & None \\
3 & Transient weakness above knee resolved by discharge \\
4 & Nausea \\
5 & Absent pulses rt. foot, had intraop rt femoral embolectony, $\downarrow$ sirenglh distal to rt. knee, weak DP at discharge \\
6 & Nausea \\
7 & Nausea, vomiting \\
8 & Nausea \\
9 & Nausea \\
10 & None \\
$1 !$ & Nausea \\
12 & None \\
13 & Nausea, vomiting \\
14 & T-wave inversion, hypotension, responded to volume, cardiac enzymes negative, inversion resolved \\
15 & Fever secondary to tumor necrosis \\
\hline
\end{tabular}

Postoperative complications encountered. All patients stayed in the intensive care unit for 1 day, except patient \#4 (2.5 days).

systemic heparinization is that leakage into the pump from the systemic circulation is a possibility with concomitant stasis (just proximal to the cannula as described by Cruchley et al.) and clot formation. ${ }^{5,13.18}$ The limb temperature is monitored simply by monitoring the perfusate temperature which is heated to $40^{\circ} \mathrm{C}$. We do not measure venous temperature, although a temperature probe could be inserted into the venous drainage line as well. We have not experienced any problem monitoring the temperature in the described manner.

Based on previous radioisotope studies, ${ }^{9.20}$ as well as our experience, the system appears to be relatively tight. The use of the reservoir to determine if a leak occurs is a good mcthod. If a lcak were to occur into the systemic circulation, one might expect to see an increase in blood pressure due to the volume infusion and an increase in temperature, since the perfusate is heated to $40^{\circ} \mathrm{C}$. $A$ rise in blood pressure might be confused with the need for a deeper level of anaesthesia. It is therefore of major importance to watch reservoir blood volume during the initiation of perfusion and once a steady flow state has been reached. If the volume of the reservoir cannot be maintained, a leak to the systemic circulation should be considered. If the volume of the reservoir continues to rise, a leak from the systemic circulation to the perfusion system is likely. Major leaks to the pump are uncommon. In our one instance this was noticed immediately and corrective measures were under- taken. In addition to the rapid infusion of an appropriate volume, this includes examination of tourniquets and repositioning them as needed. In this patient the volume infused and the temporary need for inotropic agents seemed to be in excess of the $500 \mathrm{ml}$ rise in reservoir volume. Another patient showed a significant drop in blood pressure without reservoir change. These cases suggest that initiation of perfusion in some patients is associated with significant cardiovascular changes. A likely explanation is a fall in systcmic vascular resistance as a result of exposure of the isolated limb to an increased temperature. ${ }^{21}$ If a leak occurs to the circulation from the limb, then the possibility of toxicity from the LPAM is introduced. Wagner ${ }^{10}$ describes the problems associated with LPAM systemic toxicity and those include nausea and GI slough, pancytopenia, erythema of the skin and oedema of the extremity. Table IV demonstrates the high incidence of nausea with our cases. In all but three of our cases the white blood cell count increased postoperatively and returned to near normal by the day of discharge in all cases (see Table (I). The lowest wbc count at discharge was $2900 / \mathrm{mm}^{3}$. The possibility of a two-way leak is discussed by Cruchley et al. ${ }^{18}$ They claim that this is not excluded with a stable volume in the reservoir. However, radiolabeled studies indicate that if a leak occurs it is small and therefore is not of major concern.

Other complications previously reported include 
death (described as a result of pulmonary embolus), wound infection, nerve palsy, vascular complications, pneurnonia, bone marrow depression and leukopenia. Our patients showed an increased wbc count following the procedure. As seen from Table IV, five of our patients had postoperative complications other than nausea, the most serious of which were: a transient numbness above the knee in one patient that resolved by time of discharge and a decreased dorsalis pedis pulse in the patient requiring intra-operative embolectomy. A third patient experienced T-wave inversion with hypotension on postop day one. There was no chest pain. The patient responded to volume infusion with resolution of the T-wave changes and hypotension. Cardiac enzymes were not elevated. All of our patients routinely are placed in an intensive care unit for close observation of the limb for at least one day postoperatively (see Table IV).

We have been able to successfully use the blood removed from the system, along with the haemoglobin and haematocrit of that blood, to arrive at a value for reasonable blood replacement. This method requires a rapid determination of the hgb and het of the washout be available. The formula used is a simple proportion, i.e., washout heto washout volume $=$ blood lost het $x$ blood lost volume. It converts to our formula:

blood lost $(\mathrm{ml})=$

washout het $\times$ volume of washout $(\mathrm{ml})$

patient's preop het

The determination of the haematocrit after induction, which may be associated with significant fluid infusion and therefore haemodilution, should be more accurate than the use of the preoperative value. However our data show that use of the preoperative haematocrit does provide good results.

In summary we feel that measurements of pulse blood pressure and body temperature in combination with pump reservoir volume will readily detect leaks when they occur. One may quickly detect major blood shifts between the pump oxygenator and the patient through continuous observation of these parameters. Complicated invasive monitoring is not necessary unless medically indicated. Adequate blood replacement can be determined from the volume and haemoglobin concentration of the blood recovered during extremity washout.
References

1 Klopp CT, Alford TC, Bateman J, Berry GN, Winship T. Fractionated intra-arterial cancer chemotherapy with methyl bis amine hydrochloride: a preliminary report. Ann Surg 1950; 132: 811-32.

2 Creech $O J r$, Krementz ET, Ryan RF, Wimblad JN. Chematherapy of cancer: Regional perfusion utilizing an extracorporeal circuit. Ann Surg 1958; 148 : 616-32.

3 Stehlin JS Jr. Hyperthermic perfusion with chemotherapy for cancer of the extremities. Surg Gynecol Obstet 1969; 129: 305-8.

4 Stehlin JS Jr, Giovanella $B C$, de Ipolyi $P D$, Muenz $L R$, Anderson $B A$. Results of hyperthermic perfusion for melanoma of the extremities. Surg Gynecol Obstet 1975; 140: 338-48.

5 Stehlin JS Jr, Giovanella BC, de lpolyi PD, Muenz $L R$, Anderson BA. Results of hyperthermic perfusion for melanoma of the extremities. Surg Gynecol Obstet 1975; 140: 338-348

6 Luck JM. Action of P-[D, (2-chloroethyl)]-amine L-phenylalamine on Harding-Passey mouse melanoma. Science 1956; 123: 984-5.

7 Clark $W H$. A classification of malignant melanoma in man correlated with histogenesis and biologic behavior. Montague W, Hu F eds. Advances in biology of the skin; the pigmentary systems. London, Pergamon Press 621-647 (1967).

8 Breslow A. Thickness, cross sectional areas and depth of invasion in the prognosis of cutaneous melanoma. Ann Surg 1970; 172: 902-8.

9 MCBride CM. Management of malignant melanama. In: Zollinger RM, ed. Advances in Surgery Chicago: Year Book Medical Publishers 129-150 (1974).

10 Wagner $D E$. A retrospective study of regional perfusion for melanoma. Arch Surg 1976; 11 : 410-17

11 Koops $H S$, Oldhoff $J$, Van der Plaeg E, Vormez A, Eibergen $R$, Beekhius $H$. Some aspects of the trcatment of primary malignant melanoma of the extremities by isolated regional perfusion. Cancer 1977; 39: 27-33.

12 Janoff KA, Moseson D, Nohlgren J, Davenport $C$, Richards $C$, Fletcher WS. The treatment of stage 1 melanoma of the extremities with regional hyperthermic isolation perfusion. Ann Surg 1982; 196: 316-23.

13 McBride $C M$, Clark RL. Experience in L-phenylalanine mustard dihydrochloride in isolation perfu- 
sion of extremities for malignant melanoma. Cancer 1971; 28: 1293-6.

14 Shingleton WW. Perfusion chemotherapy for recurrent melanoma of extremity: A progress report. Ann Surg 1969; 169: 969-73.

15 Sugarbaker $E V$, McBride $C M$. Survival and regional diseasc control after isolation perfusion for invasive stage [ melanoma of the extremities. Cancer 1976; 37: 188-98.

16 Stehlin JS Jr, Clark RL. Melanoma of the extremities: experience with conventional treatment and perfusion in 332 cases. Am J Surg 110: 336-83.

17 Krementz ET, Carter RD, Sutherland CM, Campbell $M$. The use of regional chemotherapy in the management of malignant melanoma. World J Surg 1979; 3: 289-302.

18 Cruchley PM, Kaplan JA, Walier JL, Young MR. Anesthesia for isolated hyperthermic limb perfusion. Ancsthesiology 1982; 57: 228-30.

19 McBride CM, Sugarbaker EV, Hickley R. Prophylactic isolation perfusion as the primary therapy for invasive malignant melanoma of the limbs. Ann Surg 1975; 182: 316-24.

20 Tonak J. Hermanek P, Banz H, Groitl H. Cytotoxics and hyperthermic perfusion: a preliminary study. Cancer Treat Rev 1979; 6(Suppl): 135-41.

21 Rowell LB, Brengelman GL, Murray JA. Cardiovascular responses to sustained high skin temperature in resting man. J Appl Physiol 1969:27: 673-B0.

\section{Résumé}

La perfusion régionale isolée de substance cytotoxique est un traitement reconnu du mélanome malin. Il n'existe pas de normes auxquelles se référer pour l'anesthésie de ces individus. Nous avons donc étudié les dossiers péri-opératoires de 15 patients nous anachan en particulier à déterminer la précision du remplacement sanguin. Nous avons relevé: (I) l'ảge, (2) l'état physique selon l'échelle ASA, (3) la présence de maladie concomitante, (4) la technique anesthésique, (5) la quanité de sang er de liquide infusé, (6) hémoglobine pré-opératoire (hgb) et hématocrite ( hol) es la formule sanguine sériée en post-opératoire. Les valeurs moyennes de remplacement de sang er de liquide ont été: culots globulaires: $2.28 \pm$ 0.82 unités $(562 \mathrm{ml})$, albumine $722 \pm 17 \mathrm{ml}$, crystalloides: $1747 \pm 21 \mathrm{ml}$. Dans cette série on retrotwait 12 malades classe I ou II et trois malades en classe III. Tous on reçu une anesthésie générale. On a retrotvé une différence statistiquement significative entre les valeurs pré: et post-opératoires pour l' hêmoglobine et l'hématocrite $(p<0,01)$ mais aucune différence entre la valeur post-opératoire et la valeur au congé du malade.

L'équation suivante permet d'assurer un remplacement liguidien suffisamment précis:

Hématocrite du perfusat à la sorice $\times$ volume da perfusat hématocrite pré-opératoire

$$
=\text { mi de sang perdil. }
$$

Il n'est pas nécessaire de recourir à un monitoring invasif impressionnant pour la perte sanguine ou la détection de fuite entre la circulation systémique el la circulation isolée. 